\title{
OECD Ülkelerinde Sağlık Harcamalarının Çekici Bir Faktör Olarak Uluslararası Göç Üzerindeki Etkisinin Panel Vector Autoregression (PVAR) Yaklaşımı ile İncelenmesi*
}

\author{
An Investigation of the Impact of Health Expenditures on International \\ Migration as a Pull Factor in OECD Countries Using a Panel Vector \\ Autoregression (PVAR) Approach
}

\section{Serdar ÖZTÜRK' ${ }^{\oplus}$, Buket ALTINÖZ² $\odot$}

\section{öz}

Uluslararası göç bireylerin bulunduğu ülke veya bölgelerden çeşitli sebeplerle zorunlu veya gönüllü olarak bir başka ülke veya bölgeye doğru bir nüfus hareketidir. Demografik bir olgu olmasının yanı sıra göçün bireylerin karar alma mekanizmalarına bağlı olarak gelişen karmaşık bir süreç olduğu bilinmektedir. Bu çalışmanın amacı sağlık ve göç arasındaki ilişkiyi ev sahibi ülke perspektifinden ele almaktır. Böylece sağlık harcamalarının ülkenin sahip olduğu göçmen nüfusa etkisi olup olmadığı tespit edilmektedir. Ayrıca sağlık harcamalarının yanı sıra göç üzerinde etkisi olabilecek büyüme ve kentleşme göstergeleri de modele dahil edilerek OECD ülkelerindeki söz konusu ilişki panel VAR yaklaşımı ile 20002017 dönemi için ele alınmıştır. Ulaşılan sonuçlar sağlık harcamalarındaki bir artışın OECD ülkelerindeki göçmen nüfusu artırdığını ortaya koymuştur. Elde edilen bu sonuç sağlık harcamalarının OECD ülkelerinde göç üzerinde çekici faktör etkisi olduğunu doğrulamıştır. Kentleşme ve ekonomik büyüme katsayılarının istatistiksel olarak anlamsızlığı tespit edilen bir başka sonuçtur. Bununla birlikte uzun dönemde sağlık harcamalarında artışın bu ülkelerde ekonomik büyümeye katkı sağladığı PVAR sonuçlarından elde edilen önemli bulgulardan biridir. Dolayısıyla, sağlık harcamaları göç kararının verilmesinde bir belirleyici olarak gerek ev sahibi gerekse kaynak ülkelerin göç politikalarında dikkate alınması gereken bir husus olarak değerlendirilmektedir. Buna ek olarak sağlık alanındaki gelişmeleri beşerî sermayenin gelişmesine katkıda bulunması yönüyle ekonomik büyüme için önemli bir dinamik olarak değerlendirmek mümkündür.

Anahtar Kelimeler: Göç, Sağlık harcamaları, PVAR, Nedensellik, OECD Jel Sınıflaması: F22; H51; C23
DOI: $10.26650 / J E P R 982598$

"Bu çalışma Prof. Dr. Serdar ÖZTÜRK

danışmanlığında Buket ALTINÖZ tarafından Nevşehir Hacı Bektaş Veli Üniversitesi Sosyal Bilimler Enstitüsü İktisat Ana Bilim Dalında hazırlanan "Uluslararası Göçe Etki Eden Faktörler: Çekici Güçler Yaklaşımı" başlıklı doktora tezinden türetilmiştir.

${ }^{1}$ Nevşehir Hacı Bektaş Veli Üniversitesi, İktisadi ve İdari Bilimler Fakültesi İktisat Anabilim Dalı, Nevşehir, Türkiye

${ }^{2}$ Dr., Nişantaşı UUniversitesi, Meslek Yüksekokulu, Muhasebe ve Vergi Uygulamaları Bölümü İstanbulTürkiye

ORCID: S.Ö. 0000-0003-0650-0244 B.A. $0000-0002-4276-4821$

\section{Sorumlu yazar/Corresponding author: Buket ALTINÖZ, \\ Nişantaşı Üniversitesi, Meslek Yüksekokulu, İstanbul, Türkiye}

E-posta/E-mail: buket.altinoz@nisantasi.edu.tr

Bassvuru/Submitted: 13.08.2021

Revizyon Talebi/Revision Requested: 9.10.2021 Son Revizyon/Last Revision Received: 10.10 .2021 Kabul/Accepted: 22.10 .2021

Atıf/Citation: Ozturk, S. \& Altinoz, B. (2022). OECD ülkelerinde sağlık harcamalarının çekici bir faktör olarak uluslararası göç üzerindeki etkisinin Panel Olarak uluslararası goç üzerindeki etkisinin
Vector Autoregression (PVAR) yaklaşımı ile incelenmesi. Iktisat Politikası Araştırmaları Dergisi Journal of Economic Policy Researches, 9(1), 39-52. https://doi.org/10.26650/JEPR982598

This work is licensed under Creative Commons Attribution-NonCommercial 4.0 International License 


\begin{abstract}
International migration refers to the compulsory or voluntary movement of people from one country or region to another country or region for various reasons. In addition to being a demographic phenomenon, it is also a complex process that develops depending on the decision-making mechanisms of individuals. This study examines the relationship between health and migration from the perspective of the host country. Thus, this paper explores whether health expenditures influence immigrant populations in host countries. In addition to health expenditures, growth and urbanization, which may impact migration, are also included in the model, and the relationship between these factors in OECD countries is discussed for the period from 2000-2017 by using a panel vector autoregression (PVAR) approach. The results show that an increase in health expenditures increases the size of immigrant populations in OECD countries. This result confirms that health expenditures function as pull factors for migration in OECD countries. Additionally, the urbanization and economic growth coefficients were observed to be statistically insignificant. Moreover, the PVAR analysis also demonstrated that, in the long run, an increase in health expenditures contributes to economic growth in these countries. Therefore, health expenditures are considered a factor in the migration policies of both host and source countries because they are a determinant in migration decisions.
\end{abstract}

Keywords: Migration, Health expenditures, PVAR, Causality, OECD

Jel Classification: $\mathrm{F} 22 ; \mathrm{H} 51 ; \mathrm{C} 23$

\title{
EXTENDED ABSTRACT
}

International migration has become a global phenomenon that affects many areas. From the perspective of development, these effects are mainly considered to be the advantages and disadvantages of international migration. As a result of migration, the population of the host country increases while the population of the origin country decreases. This demographic change has many potential effects, and a well-managed migration process makes it possible to mitigate the adverse effects of population movements. Because migration is an important issue, most countries have developed various policies on migration. Therefore, this study investigates the relationship between immigrant populations and health expenditures in OECD countries.

Studies investigating the causes of migration form the background against which this study emerged. However, the relevant literature primarily focuses on push factors that cause migration (Naude, 2010; Djafar \& Hassan, 2012; Dimant, Krieger \& Meerrieks, 2013). These factors are considered in different categories. However, both the push and pull effects of economic factors on migration decision are more dominant. In addition, although OECD countries are known to have dense immigrant populations, only a few studies have discussed the dynamics of migration in these countries (Mayda, 2007; Belot \& Ederveen, 2021). In addition, no study has directly investigated the impact of health sector development in OECD countries on immigrant populations. Thus, this study aims to fill in these gaps in the literature. For this purpose, this study adopted the PVAR approach to study the period between 2000 and 2017. In addition to health expenditures, economic growth and urbanization were also included in the model as independent variables. 
This study employed panel unit root testing procedures, determined the optimal lag length, estimated PVAR long-run coefficients, implemented causality testing, and obtained impulse-response graphs. According to the analysis, health expenditures have a positive impact on the immigrant populations of OECD countries. Moreover, an increase in health expenditures increases the size of immigrant populations in these countries by approximately $5.9 \%$. Additionally, the GDP per capita and urbanization coefficients were negative but statistically insignificant. The positive effect of health expenditures on GDP and urbanization is notable; however, its effect on urbanization is relatively minimal. As a result, it can be concluded that health expenditures are a pull factor that encourage migration to these countries. They also contribute to economic growth. After determining coefficient estimations, the causal relationships between variables was investigated. It was determined that there is a unidirectional causality relationship between health expenditures and immigrant populations. This result is compatible with the long-run coefficient estimation result. In addition, there is a unidirectional causality relationship between health expenditures and GDP per capita and urbanization. According to impulse-response functions, a standard deviation shock in health expenditures first increases the immigrant population and then subsequently decreases it. A standard deviation shock in GDP per capita first decreases immigration and then subsequently increases it. Finally, it was confirmed that a shock in urbanization does not significantly affect immigrant populations in these countries.

In line with the analysis results, it can be said that it is inevitable that migration, which refers to the movement of human capital, will be affected by health expenditures, which are defined as human capital investment. Health expenditures affect migration decisions, as they directly impact the life quality of individuals and contribute to labor productivity. Accordingly, individuals' preferences for a quality health service structure that is provided equally to all may be taken into account when defining the direct effect of health services on migration decisions. The positive effect of health expenditures on the welfare of individuals reveals the indirect effect of health sector development on migration decisions. Moreover, it is possible that reforms in the field of health, especially in origin countries, may alleviate the loss of human capital caused by migration. 


\section{Giriş}

Sağlık harcamaları bir ülkenin hem sağlık sektörü açısından durumunu yansıtan bir gösterge hem de ülkenin ekonomik kalkınmasının önemli bir belirleyicisi olarak değerlendirilmektedir. Sağlık harcamalarına verilen önem ülkenin aynı zamanda beşerî sermayesinin daha sağlıklı ve üretken olması ile bağlantılıdır. Dolayısıyla yüksek seviyelerdeki sağlık harcamaları bireyler için hem yaşam kalitesi yüksekliği hem de ülke ekonomisine pozitif katkı anlamına gelmektedir. Sağlık ve göç arasındaki bağlantı, göçmenlerin sosyo-ekonomik ve kültürel geçmişlerinden, eski sağlık deneyimlerinden ve kaynak ülkede sahip oldukları sağlık hizmetinin kalitesinden olmak üzere pek çok alt etmene bağlı karmaşık bir süreçtir. Bununla birlikte göçmenlerin daha iyi sağlık koşullarına erişim isteği ve ev sahibi ülkenin sağlık sektörü performansı bireylerin göç kararı üzerinde etkili olabilmektedir.

Göç bireylerin politik, toplumsal ve ekonomik olmak üzere çeşitli etmenlere bağlı olarak bulundukları ülkeden başka bir ülkeye kalıcı ya da geçici olarak yerleşmeleridir (Ünsal, 2019, s. 51). Tanımdan hareketle uluslararası göçün hem ev sahibi hem de menşe ülke perspektifinden ele alınması mümkündür. Dolayısıyla ev sahibi ülkelerin sahip olduğu özellikler ve imkanlar göç kararında çekici unsurlar olarak tanımlanırken, menşe ülkenin sahip olduğu koşullar itici faktörler yaklaşımıyla ele alınmaktadır. Genellikle menşe ülkenin sahip olduğu dezavantajlar kaynak ülkede göçü teşvik eden unsurlar halini almaktadır. Nitekim menşe ülkede sağlık sektöründeki yetersizlikler ve aksaklıklar bireyleri göçe iten bir faktör iken, ev sahibi ülkenin gelişmiş bir sağlık sistemine ve nitelikli sağlık personeline sahip olması göçü teşvik eden çekici bir unsur olarak değerlendirilmektedir.

Sağlık hizmetlerinin ve dolayısıyla sağlık sektörünün en önemli yönlerinden biri bireylerin yaşam kalitesi üzerinde doğrudan bir etkisi olmasıdır. Bu nedenle sağlık hizmetlerinin kapsamını belirlemek ve eşit olarak tüm insanlara sağlanmasını garanti altına almak bir insanlık meselesidir. Kamu tercihi teorisine göre sağlık hem talep hem de arz tarafında mevcut olan dışsallıklar, bilgi asimetrisi, iyi deneyim, doktor-hasta ilişkisi, ahlaki tehlike, ters seçim gibi belirli özelliklere sahip bir erdemli mal olarak tanımlanmaktadır. $\mathrm{Bu}$ ekonomik özelliği göz önüne alındığında sağlık hizmeti bireylerin karşılığını ödeme istekliliğinden ziyade ihtiyaçlara göre sağlanmalıdır. Sağlık hizmeti doğası gereği üretken bir sürecin girdisidir ve tıbbi tedavinin bir tüketim etkisi vardır. Buna göre bireyler daha sağlıklı olduklarında kendilerini daha iyi hissederek işgücü piyasasında daha aktif olurlar. Bununla birlikte sağlık sisteminin tüm ülkelerde çağın koşullarına uygun ve yeni ihtiyaçlara uyumlu bir şekilde uyarlanması gerekmektedir (Francesca \& Petretto, 2019, s. 153). Dolayısıyla sağlık hizmetleri doğrudan insan ihtiyaçlarına yönelik bir yapıya sahip olduğundan, bireylerin mevcut yaşam koşullarına doğrudan etki ederek geleceğe dair bir 
öngörü imkânı da sağlamaktadır. Böylece bireylerin göç kararı dahil olmak üzere karar alma mekanizmaları üzerindeki etkisi yadsınamaz bir gerçekliğe sahiptir.

Literatürde göçün nedenlerini araştırmaya yönelik yapılan pek çok çalışmaya rastlamak mümkündür (Mayda, 2007; Naude, 2010; Nica, 2015; Simpson, 2017; Grau \& Lopez, 2017; Dao, Docquier, Parsons, \& Peri, 2018; Arif, 2019). Bununla birlikte OECD ülkeleri için yapılan çalışmaların yaygınlığı (Mayda, 2007; Geis, Uebelmesser, \& Werding, 2013; Docquier, Peri \& Ruyssen, 2014; Ravlik, 2014; Grau \& Lopez, 2017; Drazenovic, Kunovac \& Pripuzic, 2018; Arif, 2019) bu ülkelerin sahip olduğu göçmen nüfustaki özellikle son yıllardaki artışı açıklamada önemlidir. Öte yandan sağlık harcamalarının göç için bir çekici unsur olup olmadığının belirlenmesi hususunun literatürün ihmal edilen bir yönü olduğu söylenebilir. Dolayısıyla özellikle Almanya, Amerika ve Kanada gibi yüksek göçmen nüfusa sahip ülkeleri de içine alan OECD ülke grubunda sağlık sektörüne verilen önemin göçmenlerin bu ülkelere göç kararında etkili olup olmadığının araştırılması bu çalışmanın temel amacıdır. Bu amaç etrafında çalışmada güncel ve kapsamlı bir panel veri analizi imkânı sunan panel vektör otoregresyon (PVAR) yaklaşımı benimsenmiştir. Göçün beşerî sermaye hareketliliği anlamına geldiği göz önüne alındığında menşe ülkelerin vatandaşlarını göç kararından caydırmak için veya varış ülkelerinin göçmenleri teşvik etmek için sağlık sektörü odaklı göç politikalarının şekillenmesi elde edilen bulguların temel katkısını oluşturmaktadır. Bu çalışma ile literatüre sağlanan katkı sağlık harcamalarının çekici bir unsur olarak OECD ülkelerindeki göçmen nüfusa etkisinin ilk kez ele alınmasıdır. Bir diğer katkı ise PVAR yaklaşımının benimsenmesidir. Bu yöntem ile söz konusu ilişki detaylı ve ampirik olarak sağlam ekonometrik kanıtlarla ortaya konmuştur.

Çalışmanın temel motivasyonunu göç literatürüne çekici bir unsur olarak sağlık harcamalarının dahil edilmesinin önemi oluşturmaktadır. Nitekim bireylerin çalışma ortamları, sosyal çevreleri ve dolayısıyla yaşam kalitesi ile doğrudan bağlantılı olan sağlık hizmetlerinin göç konusunda göz önüne alınması önemi her geçen gün artan göç olgusuna yeni bir bakış açısı kazandırmaktadır. Böylece göçün bir beşerî sermaye hareketi olduğu düşünüldüğünde bu beşerî sermayenin iyileşmesi ve gelişmesi için gerekli olan önkoşullardan biri olarak sağlığın göç kararındaki önemine dikkat çekilmektedir.

Çalışmanın izleyen bölümünde ampirik literatür araştırması yapılarak, bir sonraki bölümde model tanıtılmış, veri setine ilişkin açıklamalarla birlikte kullanılan ekonometrik yöntemin metodolojik açıklamalarına yer verilmiştir. Dördüncü bölüm ampirik analiz bulgularını içermektedir. Son olarak sonuç bölümünde çalışmadan elde edilen temel bulgular özetlenerek bir takım politika çıkarımları yapılmaktadır. 


\section{Literatür Araştırması}

Göçe neden olan faktörlerin araştırılması günümüzde göç politikalarının şekillenmesinde politika yapıcılara fikir vermektedir. Bu nedenle literatürde özellikle uluslararası göçün nedenlerini araştıran çalışmalar son dönemlerde önemli bir yere sahiptir. Literatür araştırması çalışmaların benimsediği örneklem grubuna odaklanılarak ele alınmıştır.

Bu çalışmanın kapsamı ile uyumlu olarak OECD ülkeleri için yapılan çalışmalardan biri Mayda (2007)'dir. Bu çalışma 14 OECD ülkesine göçün nedenlerini 1980-1995 dönemi için ele almıştır. Ulaştığı sonuçlar ev sahibi ülkenin sahip olduğu ortalama gelir firsatlarının göç oranlarını önemli ölçüde artırdığını göstermiştir. Dolayısıyla bu sonuç gelirin göç kararında etkili olan bir çekici faktör olduğunu ortaya koymuştur. Boubtane, Coulibaly ve Rault (2013) 22 OECD ülkesine ait 1980-2005 dönemi verilerini kullanarak Kònya nedensellik testi uygulamışlardır. Sonuçlara göre ev sahibi ülkedeki işsizlik bu ülkelerdeki göçmen nüfusun azalmasının nedenidir, ancak göç işsizliğin nedeni değildir. Ayrıca büyüme ev sahibi ülkede göçmen nüfusun artmasının nedeni iken göç büyümenin nedeni değildir. OECD ülkeleri için bir başka çalışma Bove, Efthyvoulou ve Pickard (2020)'dır. 36 OECD ülkesinin ele alındığı bu çalışma 1990-2016 veri dönemini kapsayarak hükümetin politik ideolojisinin göç ile ilişkisini ele alır. Analiz bulgularına göre ev sahibi ülke hükümetinin kaynak ülke hükümetinden daha solcu olması halinde göç akışı daha yoğun olmaktadır. Dolayısıyla, sol ideoloji çekici bir güçtür. Belot ve Ederveen (2021) 22 OECD ülkesinde kültürel ve kurumsal engellerin göç ile ilişkisini 1990-2003 dönemi için ele almıştır. Sonuçlar kültürel farklılıkların uluslararası göç akışları üzerindeki olumsuz etkisine dair kanıtlar sağlamıştır. Bununla birlikte kültürel engellerin gelişmiş ülkeler arasındaki göç akışlarını açıklayan önemli bir unsur olduğu tespit edilmiştir.

Jennissen (2013) Batı Avrupa ülkeleri'ne ait 1960-1998 dönemi verileri ile havuzlanmış zaman serisi regresyon analizi uygulamıştır. Sonuçlar göçmen stoku üzerinde kişi başına GSYH ve eğitim düzeyinin pozitif, işsizliğin negatif bir etkiye sahip olduğunu göstermiştir. Grau ve Lopez (2017) ise Avrupa ülkeleri için bir analiz yapmıştır. Bu çalışma nüfus, sağlık ve çevresel göstergeleri esas almıştır. Sonuçlar ekonomik büyüme ve kamu borç stokunun göç ile ilişkili olduğunu göstermiştir. Avrupa ülkeleri için bir başka çalışma Drazenovic ve ark. (2018)' ne aittir. Çekim modeli ile analiz gerçekleştirilen bu çalışmada GDP ve işgücü piyasalarının göç üzerinde etkisi olduğu ortaya çıkmıştır. Giulietti, Guzi, Kahanec ve Zimmermann (2013) 19 Avrupa ülkesine ait 1993-2008 dönemi verileri ile EKK, IV ve GMM tahmincilerini kullanarak analiz gerçekleştirmişlerdir. Sonuçlar kişi başına GSYH artışı ve istihdam koşullarının iyileşmesinin çekici birer güç olduğunu gösterirken, işsizlik yardımı harcamalarının AB üyesi olmayan ülkelerdeki göçmen nüfusu artırdığg bulgusuna ulaşmışlardır. Geis ve ark. (2013) göç kararında kurumsal belirleyicileri araştırmışlardır. Bu 
çalışmada Fransa, Almanya, İngiltere ve ABD için mikro düzeyde veriler kullanılmıştır. Elde edilen sonuçlar ücretler, sosyal ağlar ve işsizlik oranlarının göç kararlarını etkilediğini göstermiştir. Gomez ve Giraldez (2017) AB ülkelerinde göçmen nüfus ile ekonomik büyüme arasındaki nedensellik ilişkisini ele almışlardır. Danimarka Hollanda ve İzlanda' da göçmen nüfusun ekonomik büyümenin nedeni olduğunu ortaya koymuştur.

Naude (2010) farklı bir örneklem grubu benimseyerek sahra-altı Afrika ülkeleri için göçün nedenlerini ortaya koymaya çalışmıştır. Bu çalışma 45 Afrika ülkesine ait 1965-2005 dönemi verileri ile GMM tahmin yaklaşımına dayanmaktadır. Sonuçlar silahlı çatışma ve iş fırsatlarının yetersizliğinin göç kararında önemli birer belirleyici olduğunu göstermiştir. Bunlara ek olarak demografik ve çevresel baskıların nispeten daha az bir etkiye sahip olduğu elde edilen bulgularla kanıtlanmıştır. Djafar ve Hassan (2012) Malezya'daki Endonezyalı işçilerin göç kararında itici ve çekici faktörleri PVAR yaklaşımı ile araştırmışlardır. Bulgular Endonezya ve Malezya'daki gelir ve işsizlik ile Malezya'daki Endonezyalı göçmen işçiler arasında uzun dönemde bir ilişki olduğunu göstermiştir. Ayrıca, Endonezya ve Malezya'daki gelir ve işsizlikten Malezya'daki Endonezyalı göçmen işçilere doğru tek yönlü bir nedenselliğin varlı̆̆

Geniş bir panel veri seti kullanılarak yapılan çalışmalardan Dimant ve ark. (2013) yolsuzluğun göç üzerindeki etkisini 111 ülkeye ait 1985-2000 dönemi verileri ile araştırmışlardır. Elde edilen bulgular yolsuzluğun özellikle vasıflı işgücünü göçe teşvik eden önemli bir itici faktör olduğunu göstermiştir. Bu ise yolsuzluğun eğitimin getirisini azaltacağ beklentisi ile ilişkilendirilmektedir. Docquier ve ark. (2014) 2000-2010 dönemi için 138 kaynak ülke ve 30 ev sahibi ülke verilerini kullanarak yaptıkları araştırmada ev sahibi ülkenin kişi başına düşen gelir düzeyinin göçü teşvik ettiğini göstermiştir. Ravlik (2014) ülkeler arasındaki göç üzerinde etkisi olan çekici faktörleri küresel bir perspektiften ele almıştır. Çalışmada 212 menşe be 167 ev sahibi ülke verisi kullanılmıştır. İnsani gelişim endeksi, hukukun üstünlüğü, ülkeler arasındaki sömürge ilişkisi ve nüfusun göçmen stoğu üzerindeki etkisinin analiz edildiği bu çalışmadan elde edilen bulgular daha yüksek insani gelişme düzeyi, hukuki üstünlüğü ve ortak sömürge geçmişi bulunan varış ülkelerinin menşe ülkelerden göçü teşvik eden çekici unsurlar olduğunu göstermiştir. Dao ve ark. (2018) 138 kaynak ülke ve ev sahibi OECD ülkelerine odaklanmışlardır. 2000-2010 veri dönemini kapsayan çalışmada çekim modeli benimsenerek EKK analizi uygulanmıştır. Sonuçlara göre düşük vasıflı işgücünün göç isteği kişi başına GSYH artışı ile azalmaktadır. Ayrıca göçmen ağının boyutu ve dil yakınlığı göçü teşvik ederken, coğrafi uzaklık göçü azaltmaktadır. Arif ve ark. (2019) 103 ülkenin karşılıklı göç verilerini göz önüne alarak geniş bir veri seti ile uygulanan bir başka çalışmadır. Ulaşılan sonuçlar ekonomik özgürlüğün çekici bir faktör olduğunu gösterirken, ekonomik göstergelerdeki olumsuzlukların iti birer güç olarak göç kararlarına yansıdığını ortaya çıkarmıştır. 
Literatür araştırması göçün nedenlerini belirlemeye yönelik çalışmaların ilgili literatürde giderek daha fazla yer aldığını göstermektedir. Bununla birlikte çalışmalar ağırlıklı olarak itici faktörler yakalamışına odaklanmaktadır. Ayrıca sağlık harcamalarının göç kararı üzerindeki etkisini araştırmaya yönelik bir çalışmaya ampirik literatürde rastlanmamıştır. Dolayısıyla bu çalışmada OECD ülkelerinde sağlık harcamalarının gelişiminin bu ülkelere göç kararındaki etkisi araştırılarak literatürdeki boşluk giderilmeye çalışılmaktadır.

\section{Model, Veri Seti ve Yöntem}

Sağlık harcamalarının göç üzerindeki etkisinin araştırıldığı bu çalışmada Mayda (2007), Giulietti ve ark. (2013), Grau ve Lopez (2017) çalışmaları esas alınarak benimsenen temel bir panel veri modeli şöyledir:

$$
\operatorname{mig}_{i t}=\beta_{0 i}+\beta_{1 i} \text { health }_{i t}+\beta_{2 i} g d p_{i t}+\beta_{3 i} u r b_{i t}+u_{i t}
$$

Modelde i ve t sirasıyla ülke grubu (OECD ülkeleri) ve zaman periyodunu (2000-2017) ifade eder. Bağımlı değişkeni ifade eden mig OECD ülkelerindeki toplam göçmen nüfustur. Bağımsız değişkenler sırasıyla toplam kamu harcamaları içerisinde sağlık harcamalarının payı (health), kişi başına gayri safi yurtiçi hasıla $(g d p)$ ve toplam nüfus içerisinde kentsel nüfusun payı ( $u r b$ ) olarak belirlenmiştir. Bağımlı değişken OECD Göç İstatistiklerinden temin edilirken, bağımsız değişkenler Dünya Bankası veri tabanından elde edilmiştir. Tüm değişkenler modele logaritmik bir şekilde dahil edilmiştir.

Çalışmada öncelikle serilerin durağanlık sınaması Pesaran (2007) tarafından geliştirilen yatay kesit bağımlılığını göz önünde bulunduran panel birim kök testi uygulanmıştır. Testin boş hipotezi serilerin birim kök içerdiğini alternatif hipotezi ise serilerin durağan olduğunu ifade eder. Birim kök sınamasının ardından uzun dönem katsayı tahmin aşamasına geçilmektedir. Bu amaçla çalışmada panel VAR metodolojisi izlenmiştir ve yöntemin temel denklemi şu şekildedir (Abrigo \& Love, 2015):

$$
Y_{i t}=Y_{i t-1} A_{1}+Y_{i t-2} A_{2}+\cdots+Y_{i t-p} A_{p-1}+Y_{i t-p} A_{P}+X_{i t} B+u_{i t}+e_{i t}
$$

Yöntemin en büyük avantajı modeldeki tüm değişkenlerin endojen olarak analiz edilme imkânı sağlamasıdır. Bununla birlikte yöntemin kendine özgü nedensellik analizi ve etkitepki fonksiyonları sağlaması kısa dönem dinamiklerine ilişkin de bir fikir sunulmasını sağlamaktadır.

\section{Analiz Bulguları}

Analizin ilk aşaması olan birim kök sınamasına ilişkin sonuçlar aşağıda Tablo 1'de sunulmuştur. Tablo 1 CIPS birim kök testine ait hem sabitli hem de sabit ve trendli modele ilişkin düzey ve fark sonuçlarını içermektedir. 
Tablo 1: Panel Birim Kök Testi Sonuçları

\begin{tabular}{lcccc}
\hline & \multicolumn{2}{c}{ Düzey } & \multicolumn{2}{c}{ Birinci Fark } \\
\cline { 2 - 5 } Değişken & Sabit & Sabit ve trend & Sabit & Sabit ve trend \\
L.mig & $-2.206^{* *}$ & -2.283 & $-4.568^{* * *}$ & $-4.825^{* * *}$ \\
L.gdp & -1.700 & -1.574 & $-4.819^{* * *}$ & $-5.872^{* * *}$ \\
L.health & $-2.868^{* *}$ & $-2.159^{* * *}$ & $-4.625^{* * *}$ & $-4.821^{* * *}$ \\
L.urb & -1.807 & -2.390 & $-2.550^{* * *}$ & $-4.782^{* * *}$ \\
\hline
\end{tabular}

$* *$ ve *** sırasıyla $\% 5$ ve $\% 1$ istatistiksel anlamlılık düzeylerini ifade eder.

Sonuçlar incelendiğinde health değişkeninin düzeyde diğer tüm değişkenlerin birinci farkta durağan olduğu anlaşılmaktadır. Bununla birlikte tüm serilerin ortak entegrasyon derecesinin I(1) olduğunu söylemek mümkündür. Birim kök sınamasının ardından uzun dönem katsayı tahminine ilişkin sonuçlar Tablo 2'de sunulmuştur.

Tablo 2: Panel VAR katsayı tahmin sonuçları

\begin{tabular}{lcccc}
\hline Değișken & mig & health & gdp & urb \\
\hline mig & $0.193^{*}$ & -0.002 & 0.001 & 5.133 \\
health & $5.930^{*}$ & $-0.036^{* * *}$ & $0.149^{* * *}$ & $0.001^{* * *}$ \\
gdp & -1.285 & 0.016 & -0.030 & -0.000 \\
urb & -0.691 & -0.037 & -0.055 & 0.001 \\
\hline
\end{tabular}

$*, * *$ ve $* * *$ surasıyla $\% 10, \% 5, \% 1$ istatistiksel anlamlılı düzeylerini ifade eder.

Tablo 2'ye göre uzun dönemde OECD ülkelerinde ele alınan dönem içerisinde sağlık harcamalarının göçmen nüfusu artırıcı etkisi dikkat çekmektedir. Buna göre sağlık harcamalarındaki bir artış bu ülkelerdeki göçmen nüfusu yaklaşık yüzde 5.9 artırmaktadır. Ekonomik büyümeyi temsil eden kişi başına GSYH ve kentleşme katsayıları ise negatif olmakla birlikte istatistiksel olarak anlamsızdır. Öte yandan sağlık harcamalarının hem GSYH hem de kentleşme üzerindeki pozitif etkisi dikkat çekmekte ancak kentleşme üzerindeki etkisi oldukça hafiftir. Sağlık harcamalarındaki bir artış uzun dönemde bu ülkelerdeki kişi başına geliri yaklaşık yüzde 0.14 artırmaktadır. Sonuçta sağlık harcamalarının hem bu ülkelere göçü teşvik eden çekici bir unsur olduğu hem de ekonomik büyümeye katk1 sağlayan bir özelliğe sahip olduğu söylenebilir.

Tablo 3: Panel Nedensellik Testi Sonuçları

\begin{tabular}{lcccc}
\hline Değișken & mig & health & gdp & urb \\
\hline mig & & 1.480 & 0.108 & 0.007 \\
health & $6.958^{*}$ & & $6.254^{* * *}$ & $4.258^{* *}$ \\
gdp & 1.426 & 1.489 & & 0.421 \\
urb & 0.021 & 0.304 & 0.186 & 4.261 \\
All & $7.008^{* * *}$ & 2.279 & $6.277^{* * *}$ & \\
\hline
\end{tabular}

$*, * *$ ve ${ }^{* * *}$ surasıyla $\% 10, \% 5, \% 1$ istatistiksel anlamlılı düzeylerini ifade eder.

Katsayı tahminlerinin ardından değişkenler arasındaki nedensellik ilişkileri araştırılmış ve ilgili sonuçlar Tablo 3'te özetlenmiştir. Tablo 3'e göre sağlık harcamalarından göçmen nüfusa doğru tek yönlü bir nedensellik ilişkisi tespit edilmiştir. Bu sonuç uzun dönem katsayı 
tahmin sonucu ile uyumlu olarak değerlendirilmektedir. Ayrıca yine uzun dönem katsayı tahmin sonuçları ile uyumlu olarak sağlık harcamalarından kişi başına GSYH ve kentleşmeye doğru tek yönlü nedensellik ilişkisinin varlığı dikkat çekmektedir. Dolayısıyla bu ülkelerde hem sağlık harcamalarının göç kararları üzerindeki belirleyici etkisi hem de sağlık harcamalarının özellikle kişi başına gelir üzerindeki yansımaları elde edilen bulgularla doğrulanmıştır.

\section{Şekil 1. İstikrar Testi}

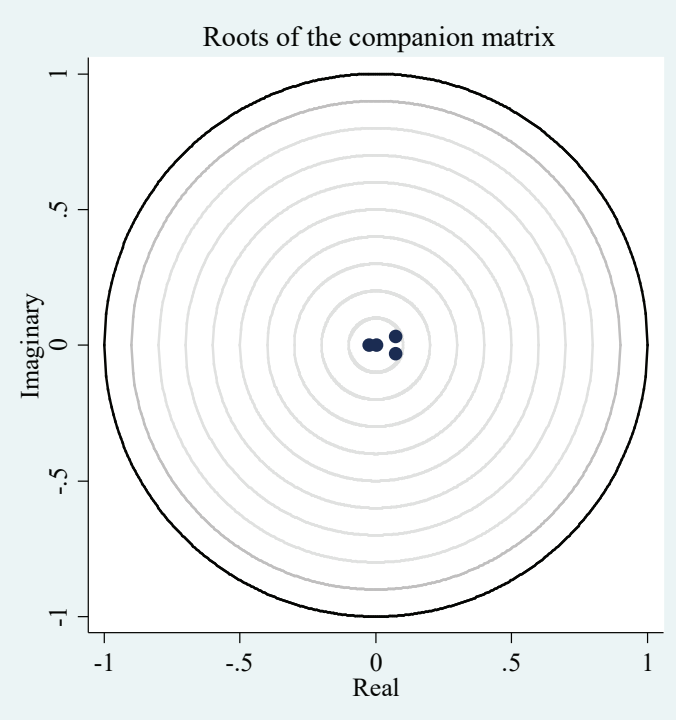

Elde edilen sonuçlar sağlık harcamaları ile göçmen nüfus arasındaki ilişkiyi doğrulamakla beraber oluşturulan modelin istikrarı sonuçların güvenilirliği açısından önem arz etmektedir. Bu nedenle panel VAR metodolojisinin sahip olduğu imkân doğrultusundan modelin istikrar testi uygulanmış ve buna ilişkin sonuç Şekil 1'de gösterilmiştir ve modelin istikrarlı olduğuna karar verilerek etki-tepki fonksiyonları araştırılmıştır. 


\section{Şekil 2. Etki-Tepki Fonksiyonları}

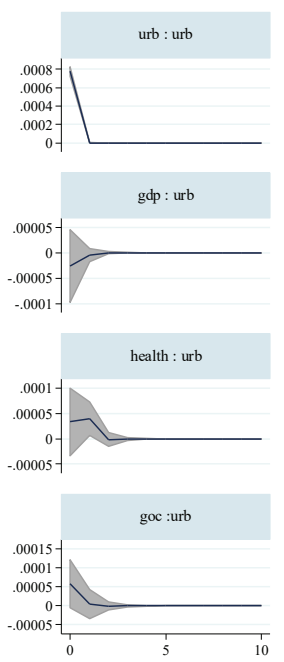

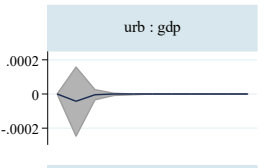

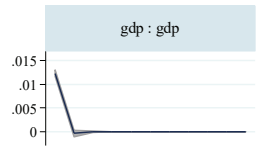

health : gdp

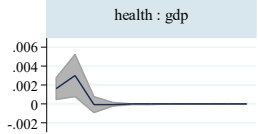

goc : gdp

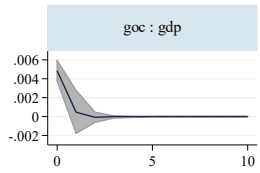

step

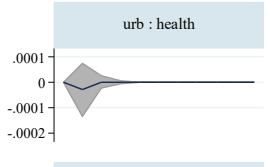

gdp : health

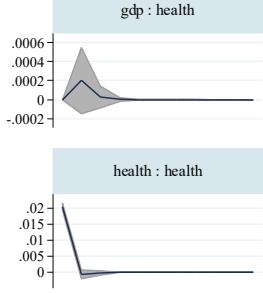

goc : health

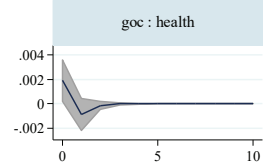
Orthogonalized IRF
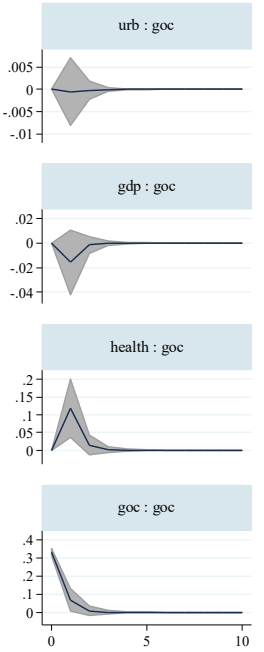

$95 \%$ CI

impulse : response

Etki-tepki fonksiyonları bağımsız değişkenlerdeki bir standart sapma şokunun bağımlı değişkendeki etkisini ortaya koymaktadır. Etki-tepki fonksiyonlarının yer aldığı Şekil 2 incelendiğinde sağlık harcamalarının önce göçmen nüfusu artırdığ 1 ancak daha sonra azalttığ1 anlaşılmaktadır. Kişi başına GSYH'daki bir standart sapma şoku göçmen nüfus üzerinde önce azaltıcı sonra artırıcı bir etkiye sahiptir. Son olarak kentleşmedeki bir şokun bu ülkelerdeki göçmen nüfusa belirgin bir etkisinin olmadığ 1 elde edilen sonuçlarla doğrulanmıştır.

\section{Sonuç}

Göç temelinde insan faktörünün yer aldığı bir yer değiştirme hareketi olduğundan esasında uluslararası göç bir beşerî sermaye hareketine karşılık gelmektedir. Dolayısıyla göç veren menşe ülkede bir beşerî sermaye azalışı karşılında göç alan varış ülkesi bir beşerî sermaye artışı ortaya çıkmaktadır. Dolayısıyla göç alan ülke için göçmenler doğal olmayan bir nüfus artışının yanı sıra fazladan işgücü anlamına da gelmektedir. Nitekim bu göçmen nüfusun gerek menşe ülke gerekse varış ülkesi için önemine ek olarak bu göç kararının belirleyicilerinin tespit edilmesi ülkelerin göç politikalarını şekillendirmektedir. Bu amaçla bu çalışmada sağlık harcamalarının OECD ülkelerindeki göçmen nüfusa etkisi araştırılarak 
sağlığa verilen önemin göç kararı için çekici bir unsur olup olmadığı araştırılmıştır. Elde edilen sonuçlar hem uzun dönem katsayı tahmini hem de kısa dönem nedensellik ve etkitepki fonksiyonları ile sağlık harcamalarının göç kararları için bir belirleyici olduğunu doğrulamıştır.

Temel sonuç etrafında bir beşerî sermaye hareketi olan göçün bir beşerî sermaye yatırımı olarak nitelendirilen sağlık harcamalarından etkilenmesinin kaçınılmaz olduğu söylenebilir. Sağlık harcamalarının bireylerin yaşam kalitesi üzerinde doğrudan etkili olması yönüyle veya işgücü verimliliğine katkı sağlaması yönüyle göç kararını etkilediği söylenebilir. Buna göre bireylerin kaliteli ve herkese eşit sağlanan bir sağlık hizmet yapısını tercih etmeleri sağlık hizmetlerinin göç kararındaki doğrudan etkisini tanımlamak için göz önünde bulundurulabilir. Bunun yanı sıra iyi bir sağlık sistemi bireylerin işgücü verimliliğinde bir iyileşme anlamlına geldiğinden uzun dönemde büyüme ve kalkınma ile ilişkilidir. Bireylerin refahını artırıcı etkiye sahip olan böylesi bir gelişme de göç kararında sağlık harcamalarının dolaylı etkisi olarak nitelendirilmektedir.

Gelişmekte olan veya az gelişmiş menşe ülkelerden daha gelişmiş ev sahibi ülkelere doğru bir beşerî sermaye kaybını azaltmak için menşe ülkelerin sağlık alanındaki yatırımlara ağırlık vermesi sağlık harcamalarının nispeten daha gelişmiş ev sahibi ülkelerdeki çekici etkisini bir dereceye kadar hafifletecektir. Buna ek olarak uzun vadede böylesi politikaların ve beşerî sermaye yatırımlarının ağırlık kazanması ile kalkınmaya yönelik dolaylı bir katkı da sağlanmış olacaktır. Ayrıca gelişmiş ev sahibi ülkelerde sağlık alanında yapılacak her ek yatırım hem göçmen nüfusun yaşam kalitesini doğrudan artıracak hem de bu nüfusun istihdam edilmesini ve işgücü piyasalarına uyum sürecini hızlandırarak uzun vadede göçmenlerin bu ülkelerin kalkınmasına katkı sağlaması mümkün hale gelecektir. Bunun için devlet tarafından daha fazla sayıda sağlık kuruluşu oluşturulmalı, nitelikli sağlık personelinin gelişimi için eğitim programları düzenlenmeli ve tamamlayıcı bir sektör olan ilaç sektörünün gelişimine yönelik atılımlar yapılmalıdır.

Sonuçta, hem gerekli işgücü ihtiyacını göçmen nüfus ile karşılayan ev sahibi ülkeler hem de göç vererek beşerî sermaye kaybıyla karşılaşan kaynak ülkeler için sağlık alanında öngörülen daha spesifik öneriler şu şekilde sıralanabilir:

- Sağlık hizmetlerinin sunulmasında kurumların nitelikli ve etkili hizmet odaklı çalışmasını sağlayacak bir kalite belirleme sistemi geliştirilmelidir. Bunun için ilgili bakanlıklar kapsamında bir kontrol sistemi oluşturulmalıdır.

- Göçmenlerin daha çok çalışma çağında olan bireylerden oluştuğu göz önüne alındığında ülkelerin işçi sağlığı konusundaki durumu önemli hale gelmektedir. Dolayısıyla ülkeler işgücünün sosyal, psikolojik ve fiziksel sağlığını tehdit etmeyen çalışma ortamlarının sağlanması konusunda işveren kurum ve kuruluşları denetlemelidir. 
- Sağlık alanında göz önünde bulundurulması gereken bir diğer husus çocuk sağlığıdır. Bebek ve çocuk ölümlerinin en aza indirilmesi temel sağlık politikalarından biri olmalıdır. Bu yönelik ücretsiz sağlık hizmetleri sunulmalı ve bu hizmetlere toplumdaki tüm çocukların eşit erişimi sağlanmalıdır.

- Sağlık kuruluşlarında gerekli olmayan tedavi ve ameliyatların önüne geçilmesi sağlık hizmetlerinin etkinliğini artırıcı bir başka önlemdir. Böylece kaynakların gerekli durum ve koşullarda ihtiyaç sahibi bireylere sunulması mümkün hale gelir.

$\mathrm{Bu}$ çalışma ile beşerî sermaye yatırımları sağlık bağlamında ele alınmış olup gelecek çalışmalarda eğitime yönelik yatırımlar gibi farklı göstergelerin analizlere dahil edilmesi, farklı metodolojik yaklaşımlarla yeni bakış açılarının sunulması ve/veya farklı örneklem grupları üzerine araştırmalar yapılarak göç literatüründe göç kararında etkisi olabilecek hem çekici hem de itici unsurların belirlenmesine yönelik alanın geliştirilmesi yönündeki gelişmelerin sağlanması umut edilmektedir.

Bilgilendirilmiş Onam: Katılımcılardan bilgilendirilmiş onam alınmıştır.

Hakem Değerlendirmesi: Dış bağımsız.

Çıkar Çatışması: Yazarlar çıkar çatışması bildirmemiştir.

Yazar Katkıları: Çalışma Konsepti/Tasarım- S.Ö.; Veri Toplama- B.A.; Veri Analizi/Yorumlama- B.A., S.Ö.; Yazı Taslağı- S.Ö., B.A.; İçeriğin Eleştirel İncelemesi- S.Ö., B.A.; Son Onay ve Sorumluluk- S.Ö., B.A.

Finansal Destek: Yazarlar bu çalışma için finansal destek almadığını beyan etmiştir.

Informed Consent: Written consent was obtained from the participants.

Peer-review: Externally peer-reviewed.

Author Contributions: Conception/Design of Study- S.Ö.; Data Acquisition- B.A.; Data Analysis/Interpretation- B.A., S.Ö.; Drafting Manuscript- S.Ö., B.A.; Critical Revision of Manuscript- S.Ö., B.A.; Final Approval and Accountability- S.Ö., B.A.

Conflict of Interest: The authors have no conflict of interest to declare.

Grant Support: The authors declared that this study has received no financial support

\section{Kaynakça/References}

Abrigo, M. R. M. \& Love, I. (2015) Estimation of panel vector autoregressive in Stata: A package of programs. Web: http://paneldataconference2015.ceu.hu/Program/Michael-Abrigo.pdf.

Arif, I. (2019). The determinants of international migration: Unbundling the role of economic, political and social institutions. World Economy, 1(1), 5-15. https://doi.org/10.1111/twec.12889.

Belot, M., \& Ederveen, S. (2012). Cultural barriers in migration between OECD countries. Journal of Population Economics, 25(3), 1077-1105.

Boubtane, E., Coulibaly, D., \& Rault, C. (2013). Immigration, unemployment and GDP in the host country: Bootstrap panel Granger causality analysis on OECD countries. Economic Modelling, 33, 261-269.

Bove, V., Efthyvoulou, G., \& Pickard, H. (2020). Government ideology and international migration (Sheffield Economic Research Paper Series No. 2020004).

Dao, T. H., Docquier, F., Parsons, C., \& Peri, G. (2018). Migration and developments: Dissecting the anatomy of the mobility transition. Journal of Development Economics, 132, 88-101. https://doi.org/10.1016/j. jdeveco.2017.12.003 
Dimant, E., Kriger, T., \& Meierrieks, D. (2013). The effect ef corruption on migration, 1985-2000. Applied Economics Letters, 20(13), 1270-1274. https://dx.doi.org/10.1080/13504851.2013.806776

Djafar, F. \& Hassan, M. K. H. (2012). Dynamics of Push and Pull Factors of Migrant Workers in Developing Countries: The Case of Indonesian Workers in Malaysia. Journal of Economics and Behavioral Studies, 4(12), 703-711.

Docquier, F., Peri, G., \& Ruyssen, I. (2014). The cross-country determinants of potential and actual migration. International Migration Review, 48, 37-99.

Drazenovic, I., Kunovac, M., \& Pripuzic, D. (2018, June). Dynamics and determinants of migration - The case of Croatia and experience of new EU member states. The Twenty-Fourth Dubrovnik Economic Conference, Dubrovnic, Croatia.

Francesca, G. C. \& Petretto, A. (2019). Health care and migration: What data can tell us of the hard-to-measure impact of migrants on the European health system. In. Dobrescu P. (Eds.), Development in Turbulent Times. Springer, Cham. https://doi.org/10.1007/978-3-030-11361-2_11

Geis, W., Uebelmesser, S., \& Werding M. (2013). How do migrants choose their destination country? An analysis of instituional determinants. Review of International Economics, 21(5), 825-840.

Giulietti, C., Guzi, M., Kahanec, M., \& Zimmermann, K. F. (2013). Unemployment benefits and immigration: Evidence from the EU. International Journal of Manpower, 34(1), 24-38.

Gomez, M. G. \& Giraldez, S. O. (2017). The causality between economic growth and immigration in EU/EFTA member states (Departamento de Economia Aplicada Working Paper No. 17/1).

Grau, A. J. G. \& Lopez, F. R. (2017). Determinants of immigration in Europe. The relevance of life expectancy and environmental sustainability. Sustainability, 9, 1093.

Jennissen, R. (2013). Economic determinants of net international migration in Western Europe. European Journal of Population, 19, 171-198.

Mayda, A. M. (2007). International migration: A panel data analysis of the determinants of bilateral flows (Centre for Research and Analysis of Migration Discussion Paper Series, No: 07/07).

Naude, W. (2010). The determinants of migration from Sub-Saharan African countries. Journal of African Economies, 19(3), 330-356. https://doi.org/10.1093/jae/ejq004

Nica, E. (2015). Labor market determinants of migration flows in Europe. Sustainability, 7(1), 634-647. https://doi. org/10.3390/su7010634

Pesaran M. H. (2007) A simple panel unit root test in the presence of cross-section dependence. Journal of Applied Econometrics, 22(2):265-312

Ravlik, M. (2014). Determinants of international migration: A global analysis (National Research University (Higher School of Economics) Working Papers, WP BRP 52/SOC/2014).

Simpson, N. B. (2017). Demographic and economic determinants of migration push and pull factors drive the decision tos tay or move (IZA World of Labor, 2017:373). https://doi.org/10.15185/izawol.373

Ünsal, A. (2019). Uluslararası göç kavramı ve uluslararası göçün ülke ekonomileri üzerinde muhtemel etkileri. Selçuk Üniversitesi Sosyal ve Teknik Araştırmalar Dergisi, 18, 50-61. 